\title{
Impact of a board certification system and implementation of clinical practice guidelines for pancreatic cancer on mortality of pancreaticoduodenectomy
}

\author{
Masamichi Mizuma ${ }^{1} \cdot$ Hiroyuki Yamamoto $^{2} \cdot$ Hiroaki Miyata $^{2} \cdot$ Mitsukazu Gotoh $^{3} \cdot$ Michiaki Unno $^{1} \cdot$

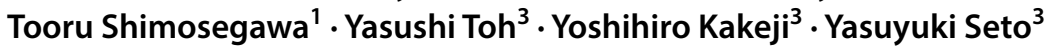

Received: 18 February 2020 / Accepted: 14 April 2020 / Published online: 7 May 2020

(C) The Author(s) 2020

\begin{abstract}
Purposes The aim of this study was to clarify the impact of a board certification system and the implementation of clinical practice guidelines for pancreatic cancer (PC) on the mortality of pancreaticoduodenectomy in Japan.

Methods By a web questionnaire survey via the National Clinical Database (NCD) for departments participating in the $\mathrm{NCD}$, quality indicators (QIs) related to the treatment for PC, namely the board certification systems of various societies and the adherence to clinical practice guidelines for PC, were investigated between October 2014 and January 2015. A multivariable logistic regression analysis was performed to evaluate the relationship between the QIs and mortality of pancreaticoduodenectomy.

Results Of 1415 departments that registered at least 1 pancreaticoduodenectomy between 2013 and 2014 in NCD, 631 departments (44.6\%), which performed pancreaticoduodenectomy for a total of 11,684 cases, answered the questionnaire. The mortality of pancreaticoduodenectomy was positively affected by the board certification systems of the Japanese Society of Gastroenterological Surgery, Japanese Society of Hepato-Biliary-Pancreatic Surgery, Japanese Society of Gastroenterology, and Japanese Society of Medical Oncology as well as by institutions that used magnetic resonance imaging of $\geq 3 \mathrm{~T}$ for the diagnosis of PC in principle.

Conclusions The measurement of the appropriate QIs is suggested to help improve the mortality in pancreaticoduodenectomy. Masamichi Mizuma and Hiroyuki Yamamoto equally contributed
\end{abstract}

Keywords Pancreaticoduodenectomy · Pancreatic cancer $\cdot$ Quality indicator · Board certification $\cdot$ Clinical practice guideline

\begin{tabular}{|c|c|c|c|}
\hline \multicolumn{2}{|c|}{ Abbreviations } & $\mathrm{CT}$ & Computed tomography \\
\hline ADL & Activity of daily life & JSGE & Japanese Society of Gastroenterology \\
\hline \multirow{2}{*}{$\begin{array}{l}\text { AOR } \\
\text { APTT }\end{array}$} & Adjusted odds ratio & JSGS & Japanese Society of Gastroenterological \\
\hline & Activated partial thromboplastin time & & Surgery \\
\hline ASA & American Society of Anesthesiologists & JSHBPS & Japanese Society of Hepato-Biliary-Pancreatic \\
\hline BMI & Body mass index & & Surgery \\
\hline $\mathrm{CA}$ & Celiac artery & JSMO & Japanese Society of Medical Oncology \\
\hline \multirow[t]{2}{*}{ CI } & Confidence interval & JSS & Japan Surgical Society \\
\hline & & MRI & Magnetic resonance imaging \\
\hline \multirow{3}{*}{$\triangle \mathrm{Mi}$} & & NCD & National Clinical Database \\
\hline & @zu Gotoh & PD & Pancreaticoduodenectomy \\
\hline & ॠinlu.ac.jp & PT-INR & Prothrombin time- international normalized \\
\hline Jap & ancreas Society, Osaka, Japan & & ratio \\
\hline \multirow{2}{*}{$\begin{array}{l}\mathrm{De} \\
\mathrm{Sc}\end{array}$} & nent of Healthcare Quality Assessment, Graduate & QI & Quality indicator \\
\hline & of Medicine, The University of Tokyo, Tokyo, Japan & SMA & Superior mesenteric artery \\
\hline $\mathrm{T}$ & anese Society of Gastroenterological Surgery, Tokyo, & WBC & White blood cell \\
\hline
\end{tabular}




\section{Introduction}

Quality indicators (QIs) are utilized to measure the quality of care, which can be defined as "the degree to which health services for individuals and populations increase the likelihood of desired health outcomes and are consistent with current professional knowledge" [1]. The quality of care has been reported to be evaluated from three aspects: "structure", "process" and "outcome" [2]. For example, board-certified experts are an indicator of structure. In addition, diagnostic methods or treatments recommended in a clinical practice guideline correspond to process indicators. The evaluation and improvement of the quality of care in each institution ultimately lead to the uniform accessibility of medical care nationwide. Therefore, assessing the quality of care using QIs is very important.

The registration of surgical cases in the National Clinical Database (NCD), which is linked to the board certification system of some surgical societies, began in 2011. Most surgical cases (90\%-95\%) performed in Japan are included in the NCD [3]. Approximately 10,000 cases of pancreaticoduodenectomy (PD), classified as having a high degree of difficulty in the surgical difficulty category defined by the Japanese Society of Gastroenterological Surgery (JSGS), are registered per year on NCD [4]. Risk models of the eight main procedures, including PD, were created using NCD data [5-12] and are used in the risk calculator on the NCD web site, which is available in clinical settings. PD is still a high-risk procedure, and the operative mortality and morbidity need improvement. The evaluation of QIs related to PD is thought to contribute to the improvement of the surgical outcome.

A questionnaire survey of the board certification system and the implementation of clinical practice guidelines for cancers of the esophagus, stomach, colorectum, liver, pancreas, biliary tract, lung and breast was conducted using the NCD to investigate their impact on the surgical mortality by a study group for "the utilization of high-accuracy organ cancer registration in the clinical practice guidelines and medical specialist training" and was supported by a grant from the Ministry of Health, Labour and Welfare of Japan. The results concerning esophageal and colon cancers have been recently reported [13, 14].

The present study aimed to elucidate the impact of the board certification system and the adherence to the clinical practice guideline for pancreatic cancer on mortality of PD.

\section{Methods}

\section{Web questionnaire using the NCD registration system}

The questionnaire form was created with the NCD registration system. The questionnaire survey of the QIs related to the treatment for pancreatic cancer was performed via the NCD web page between October 1, 2014, and January 31,2015 . The QIs of the questionnaire, which were chosen by discussion among experts on pancreatic diseases (MM, MU, TS and MG), are shown in Table 1. Q1-16, mainly asking whether or not there is a board-certified expert in each society related to the treatment of pancreatic cancer, were created as structure indicators. Q3 regarding boardcertified institutions of the Japanese Society of HepatoBiliary-Pancreatic Surgery (JSHBPS) was answered separately for Training Institutions $\mathrm{A}$ and $\mathrm{B}$. In the application for the board certification system of JSHBPS, Training Institutions A and B need to perform 50 and 30 high-level hepato-biliary-pancreatic surgeries annually, as defined by the JSHBPS, respectively [15]. Board-certified experts of the Japanese Society of Gastroenterology (JSGE) or Japanese Society of Medical Oncology (JSMO), who are not necessarily surgeons, may participate in preoperative care for PD. Thus, the board certification systems of the JSGE and JSMO were considered for the questionnaire because they may affect the outcomes of PD. Q17-22 were selected as process indicators from Clinical Questions (CQs) of Clinical Practice Guidelines for Pancreatic Cancer Based on Evidence-Based Medicine 2013 [16]. The subjects of the questionnaire were a total of 1415 departments that performed at least 1 case of PD between 2013 and 2014, including a total of 20,183 PD cases in this study (Fig. 1).

\section{Operative mortality for each QI}

Responses to the QI questionnaire were obtained from 631 departments (44.6\%), which performed 11,684 pancreaticoduodenectomies $(57.9 \%)$ during the study period. These PD cases were analyzed using the NCD database. Operative death was observed in 292 cases (2.5\%) (Fig. 1). Operative death was defined as any death within the index hospitalization period up to 90 days after surgery or any death after discharge within 30 days after surgery. The operative mortality was analyzed for each QI of the questionnaire.

\section{The multivariable logistic regression analysis}

The relationship between each QI of the questionnaires and operative death was analyzed by multivariable logistic 
Table 1 Questionnaire items related to the treatment of pancreatic cancer

\begin{tabular}{|c|c|}
\hline \multicolumn{2}{|c|}{ Structure indicator } \\
\hline Q1 & Is your institution accredited by or related to the Japan Surgical Society (JSS)? \\
\hline Q2 & Is your institution certified by the Japanese Society of Gastroenterological Surgery (JSGS)? \\
\hline Q3 & $\begin{array}{l}\text { Is your institution a board-certified training institution (Hepatobiliary-Pancreatic field) of the Japanese Society of Hepato-Biliary- } \\
\text { Pancreatic Surgery (JSHBPS)? }\end{array}$ \\
\hline Q4 & Is your institution certified by or related to the Japanese Society of Gastroenterology (JSGE)? \\
\hline Q5 & Is your institution an accredited training facility of the Japanese Society of Medical Oncology (JSMO)? \\
\hline Q6 & $\begin{array}{l}\text { Does your institution register cases of pancreatic cancer in the Japan Pancreatic Cancer Registry of the National Clinical Database } \\
\text { (NCD)? }\end{array}$ \\
\hline Q7 & Does your institution have a board-certified instructor of JSS? \\
\hline Q8 & Does your institution have an expert surgeon of gastroenterological surgery board-certified by JSGS? \\
\hline Q9 & Does your institution have an instructor of gastroenterological surgery board-certified by JSGS? \\
\hline Q10 & Does your institution have a board-certified expert surgeon (Hepatobiliary-Pancreatic field) by JSHBPS? \\
\hline Q11 & Does your institution have an instructor (Hepatobiliary-Pancreatic field) board-certified by JSHBPS? \\
\hline Q12 & Does your institution have a gastroenterologist board-certified by JSGE? \\
\hline Q13 & Does your institution have an instructor of gastroenterology board-certified by JSGE? \\
\hline Q14 & Does your institution have an oncologist board-certified by JSMO? \\
\hline Q15 & Does your institution have an instructor of oncology board-certified by JSMO? \\
\hline Q16 & Does your institution have a General Clinical Oncologist certified by the Japanese Board of Cancer Therapy? \\
\hline \multicolumn{2}{|r|}{ Process indicator } \\
\hline Q17 & Are contrast media used in CT or MRI to diagnose pancreatic cancer? \\
\hline Q18 & Is MRI of $3 \mathrm{~T}$ or more performed to diagnose pancreatic cancer? \\
\hline Q19 & $\begin{array}{l}\text { Is radical resection performed for cases with Stage 0-IVa* pancreatic cancer without invasion of SMA or CA? Or does your insti- } \\
\text { tution refer them to other institutions for radical resection? } \\
\text { * General Rules for the Study of Pancreatic Cancer the 6th Edition (the 3rd English Edition) by Japan Pancreas Society }\end{array}$ \\
\hline Q20 & Is $\mathrm{S}-1$ monotherapy performed as the first choice in adjuvant chemotherapy for pancreatic cancer \\
\hline Q21 & Is chemoradiotherapy or chemotherapy performed as the first-line therapy for locally advanced unresectable pancreatic cancer? \\
\hline Q22 & $\begin{array}{l}\text { Is either gemcitabine monotherapy, gemcitabine plus erlotinib combination therapy, or S-1 monotherapy performed as the first-line } \\
\text { chemotherapy for locally advanced unresectable or metastatic pancreatic cancer? }\end{array}$ \\
\hline
\end{tabular}

$C A$ celiac artery, $C T$ computed tomography, JSGE Japanese Society of Gastroenterology, JSGS Japanese Society of Gastroenterological Surgery, JSHBPS Japanese Society of Hepato-Biliary-Pancreatic Surgery, JSMO Japanese Society of Medical Oncology, JSS Japan Surgical Society, MRI magnetic resonance imaging, $N C D$ National Clinical Database, SMA superior mesenteric artery

regression models fitted with a generalized estimating equation, considering the clustering of patients by the hospital level. According to a previous report on the risk model using the NCD [5], the following variables were used to adjust risk factors by the patient background: age, respiratory distress (any), the activity of daily life (ADL) within 30 days before surgery (any assistance), angina, weight loss $>10 \%$, American Society of Anesthesiologists (ASA) performance status grade $\geq$ Class 3 , Brinkman index $>400$, body mass index $(\mathrm{BMI})>25 \mathrm{~kg} /$ $\mathrm{m}^{2}$, serum creatinine $>3 \mathrm{mg} / \mathrm{dl}$, platelet count $<120,000 /$ $\mu 1$, prothrombin time- international normalized ratio (PTINR) $>1.1$, white blood cell (WBC) count $>11,000 / \mu 1$ and activated partial thromboplastin time (APTT) $>40 \mathrm{~s}$. Q1 and Q17 were excluded from the multivariable analysis because very few departments answered "no" and "Not performed in principle", respectively.

\section{Statistical analyses}

The STATA 15 software program (STATA Corp., College Station, TX, USA) was used for all statistical analyses. The significance of categorical variates was calculated using the chi-square test or Fisher's exact test. The risk-adjusted odds ratio (AOR) and $95 \%$ confidence interval (CI) were calculated in multivariable logistic regression analyses. $P<0.05$ was considered statistically significant.

This specific project was approved by the Ethics Committee of Fukushima Medical University (No. 1057). 


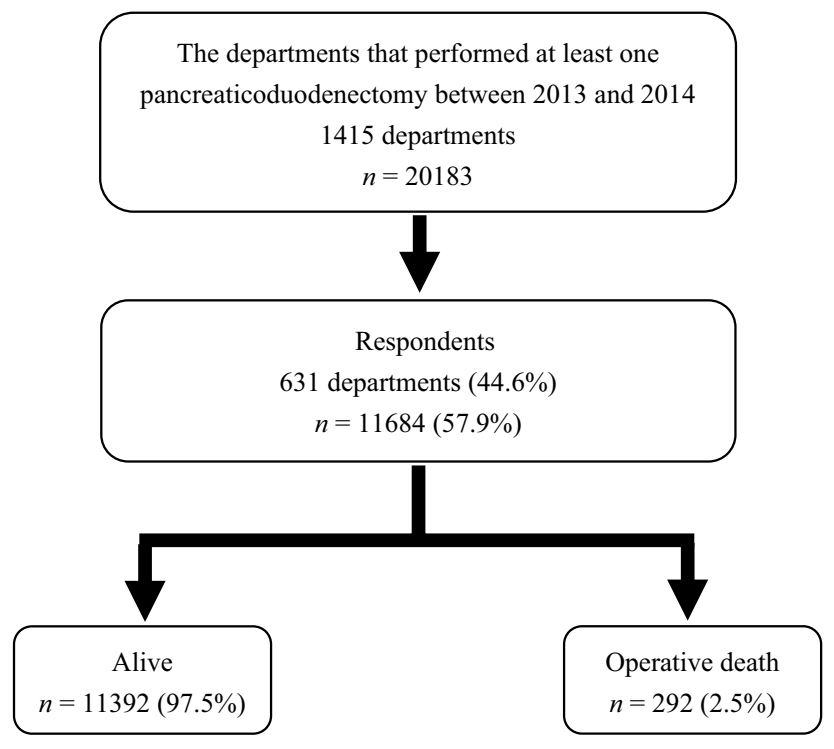

Fig. 1 The flow chart of the patient selection process

\section{Results}

\section{Patient demographics and crude operative mortality}

The crude operative mortality was investigated for each risk factor according to the previous report of the risk model for PD (Table 2) [5]. All risk model variables except for a Brinkman index $>400$ were significantly correlated with operative death.

\section{The response distribution and crude operative mortality for each QI}

Tables 3 and 4 indicate the response distribution and crude operative mortality rate in each QI for the structure and process indicators, respectively.

As shown in Qs2-5, the board-certified institutions of the JSGS, JSHBPS, JSGE, and JSMO showed a significantly lower mortality rate than the non-certified institutions $(p<0.001)$. Regarding QIs related to board-certified experts or instructors, institutions having an expert surgeon and instructor board-certified by the JSHBPS $(p<0.001)$, a gastroenterologist and instructor board-certified by the JSGE $(p=0.004$ and $p<0.001)$, and an oncologist and instructor board-certified by the JSMO ( $p=0.001$ and $p=0.004)$ showed significantly lower operative mortality than others (Table 3).

However, regarding QIs for process indicators, departments that used magnetic resonance imaging (MRI) of $\geq 3 \mathrm{~T}$ for the diagnosis of pancreatic cancer in principle $(p<0.001)$, performed radical resection for pancreatic
Table 2 Preoperative factors and crude operative mortality rates

\begin{tabular}{|c|c|c|c|c|c|}
\hline \multirow[t]{2}{*}{ Variables } & \multicolumn{2}{|c|}{$\begin{array}{l}\text { Opera- } \\
\text { tive death } \\
(n=292)\end{array}$} & \multicolumn{2}{|c|}{$\begin{array}{l}\text { Alive } \\
(n=11,392)\end{array}$} & \multirow[t]{2}{*}{$p$ value } \\
\hline & $N$ & $\%$ & $N$ & $\%$ & \\
\hline Age (years) & & & & & $<0.001$ \\
\hline$\leq 59$ & 14 & 4.8 & 1726 & 15.2 & \\
\hline $60-64$ & 24 & 8.2 & 1558 & 13.7 & \\
\hline $65-69$ & 56 & 19.2 & 2132 & 18.7 & \\
\hline $70-74$ & 68 & 23.3 & 2541 & 22.3 & \\
\hline $75-79$ & 70 & 24.0 & 2134 & 18.7 & \\
\hline$\geq 80$ & 60 & 20.5 & 1301 & 11.4 & \\
\hline Respiratory distress (any) & 5 & 1.7 & 82 & 0.7 & $0.067 *$ \\
\hline $\begin{array}{l}\text { ADL within } 30 \text { days before } \\
\text { surgery (any assistance) }\end{array}$ & 25 & 8.6 & 263 & 2.3 & $<0.001$ \\
\hline Angina & 12 & 4.1 & 118 & 1.0 & $<0.001$ \\
\hline Weight loss $>10 \%$ & 30 & 10.3 & 634 & 5.6 & 0.001 \\
\hline ASA $\geq$ Class 3 & 87 & 29.8 & 1244 & 10.9 & $<0.001$ \\
\hline Brinkman index $>400$ & 96 & 32.9 & 3511 & 30.8 & 0.452 \\
\hline $\mathrm{BMI}>25 \mathrm{~kg} / \mathrm{m}^{2}$ & 78 & 26.7 & 1789 & 15.7 & $<0.001$ \\
\hline Creatinine $>3 \mathrm{mg} / \mathrm{dl}$ & 13 & 4.5 & 79 & 0.7 & $<0.001$ \\
\hline Platelet $<120,000 / \mu 1$ & 19 & 6.5 & 352 & 3.1 & 0.001 \\
\hline PT-INR > 1.1 & 55 & 18.8 & 1308 & 11.5 & $<0.001$ \\
\hline $\mathrm{WBC}>11,000 / \mu 1$ & 13 & 4.5 & 260 & 2.3 & 0.015 \\
\hline $\mathrm{APTT}>40 \mathrm{~s}$ & 20 & 6.8 & 433 & 3.8 & 0.008 \\
\hline
\end{tabular}

$A D L$ activity of daily life, $A P T T$ activated partial thromboplastin time, ASA American Society of Anesthesiologists, BMI body mass index, $P T$-INR prothrombin time-international normalized ratio, $W B C$ white blood cell

*Fisher's exact test

cancer or referred the case to other institutions for radical resection in principle $(p=0.018)$ and performed $\mathrm{S}-1$ adjuvant therapy for pancreatic cancer in principle $(p=0.001)$ showed a significantly lower operative mortality rate than others (Table 4). In Q18, 285 departments (45.2\%) responded with "Performed in principle" concerning the use of MRI of $\geq 3 \mathrm{~T}$ for the diagnosis of pancreatic cancer.

\section{Results of the multivariable logistic regression analysis}

Figure 2 and 3 show the AOR and 95\% CI for each structure and process-related QI according to a multivariable logistic regression analysis with risk-adjustment using patient-level risk factors.

The AOR was significantly higher in institutions not certified by the JSGS (1.78 [1.19-2.66], $p<0.001)$ or JMSO $(1.69$ [1.29-2.21], $p<0.001)$ than in those that were certified (Fig. 2a, d). Compared with institutions that were not boardcertified by the JSHBPS, JSHBPS board-certified training institution A showed a significantly lower AOR (0.49 
Table 3 The response distributions and relationship between each quality indicator and the crude operative mortality: structure indicator

\begin{tabular}{|c|c|c|c|c|c|c|c|c|}
\hline \multirow[t]{2}{*}{ Questionnaire item } & \multirow[t]{2}{*}{ Department $(N)$} & \multicolumn{2}{|c|}{$\begin{array}{l}\text { Opera- } \\
\text { tive death } \\
(n=292)\end{array}$} & \multicolumn{2}{|c|}{$\begin{array}{l}\text { Alive } \\
(n=11,392)\end{array}$} & \multicolumn{2}{|l|}{ Total } & \multirow[t]{2}{*}{ Mortality rate } \\
\hline & & $N$ & $\%$ & $N$ & $\%$ & $N$ & $\%$ & \\
\hline \multicolumn{8}{|c|}{ Q1 Institution accredited by or related to JSS } & $p=0.162 *$ \\
\hline No & 7 & 2 & 0.7 & 39 & 0.3 & 41 & 0.4 & $4.88 \%$ \\
\hline Accredited & 527 & 274 & 93.8 & 10,908 & 95.8 & 11,182 & 95.7 & $2.45 \%$ \\
\hline Related & 97 & 16 & 5.5 & 445 & 3.9 & 461 & 3.9 & $3.47 \%$ \\
\hline \multicolumn{8}{|c|}{ Q2 Institution certified by JSGS } & $p<0.001$ \\
\hline Yes & 493 & 256 & 87.7 & 10,626 & 93.3 & 10,882 & 93.1 & $2.35 \%$ \\
\hline No & 138 & 36 & 12.3 & 766 & 6.7 & 802 & 6.9 & $4.49 \%$ \\
\hline \multicolumn{8}{|c|}{ Q3 A JSHBPS board-certified training institution } & $p<0.001$ \\
\hline No & 473 & 163 & 55.8 & 4370 & 38.4 & 4533 & 38.8 & $3.60 \%$ \\
\hline Training Institution A & 96 & 81 & 27.7 & 5223 & 45.8 & 5304 & 45.4 & $1.53 \%$ \\
\hline Training Institution B & 62 & 48 & 16.4 & 1799 & 15.8 & 1847 & 15.8 & $2.60 \%$ \\
\hline \multicolumn{8}{|c|}{ Q4 Institution certified by or related to JSGE } & $p<0.001$ \\
\hline No & 112 & 35 & 12.0 & 716 & 6.3 & 751 & 6.4 & $4.66 \%$ \\
\hline Accredited & 425 & 230 & 78.8 & 10,010 & 87.9 & 10,240 & 87.6 & $2.25 \%$ \\
\hline Related & 94 & 27 & 9.2 & 666 & 5.8 & 693 & 5.9 & $3.90 \%$ \\
\hline \multicolumn{8}{|c|}{ Q5 An accredited training facility of JSMO } & $p<0.001$ \\
\hline Yes & 180 & 116 & 39.7 & 6201 & 54.4 & 6317 & 54.1 & $1.84 \%$ \\
\hline No & 451 & 176 & 60.3 & 5191 & 45.6 & 5367 & 45.9 & $3.28 \%$ \\
\hline \multicolumn{8}{|c|}{ Q6 Registration in the Japan Pancreatic Cancer Registry of NCD } & $p=0.574$ \\
\hline All cases registered & 449 & 210 & 71.9 & 8400 & 73.7 & 8610 & 73.7 & $2.44 \%$ \\
\hline Some cases registered & 113 & 45 & 15.4 & 1768 & 15.5 & 1813 & 15.5 & $2.48 \%$ \\
\hline Not registered & 69 & 37 & 12.7 & 1224 & 10.7 & 1261 & 10.8 & $2.93 \%$ \\
\hline \multicolumn{8}{|c|}{ Q7 A JSS board-certified instructor } & $p=1.000^{*}$ \\
\hline Yes & 600 & 289 & 99.0 & 11,250 & 98.8 & 11,539 & 98.8 & $2.50 \%$ \\
\hline No & 31 & 3 & 1.0 & 142 & 1.2 & 145 & 1.2 & $2.07 \%$ \\
\hline \multicolumn{8}{|c|}{ Q8 A JSGS board-certified expert surgeon of gastroenterological surgery } & $p=0.408 *$ \\
\hline Yes & 605 & 287 & 98.3 & 11,255 & 98.8 & 11,542 & 98.8 & $2.49 \%$ \\
\hline No & 26 & 5 & 1.7 & 137 & 1.2 & 142 & 1.2 & $3.52 \%$ \\
\hline \multicolumn{8}{|c|}{ Q9 A JSGS board-certified instructor of gastroenterological surgery } & $p=0.081$ \\
\hline Yes & 559 & 274 & 93.8 & 10,925 & 95.9 & 11,199 & 95.8 & $2.45 \%$ \\
\hline No & 72 & 18 & 6.2 & 467 & 4.1 & 485 & 4.2 & $3.71 \%$ \\
\hline \multicolumn{8}{|c|}{ Q10 A JSHBPS board-certified expert surgeon } & $p<0.001$ \\
\hline Yes & 120 & 89 & 30.5 & 4688 & 41.2 & 4777 & 40.9 & $1.86 \%$ \\
\hline No & 511 & 203 & 69.5 & 6704 & 58.8 & 6907 & 59.1 & $2.94 \%$ \\
\hline \multicolumn{8}{|c|}{ Q11 A JSHBPS board-certified instructor } & $p<0.001$ \\
\hline Yes & 241 & 164 & 56.2 & 7938 & 69.7 & 8102 & 69.3 & $2.02 \%$ \\
\hline No & 390 & 128 & 43.8 & 3454 & 30.3 & 3582 & 30.7 & $3.57 \%$ \\
\hline \multicolumn{8}{|c|}{ Q12 A JSGE board-certified gastroenterologist } & $p=0.004$ \\
\hline Yes & 560 & 270 & 92.5 & 10,923 & 95.9 & 11,193 & 95.8 & $2.41 \%$ \\
\hline No & 71 & 22 & 7.5 & 469 & 4.1 & 491 & 4.2 & $4.48 \%$ \\
\hline \multicolumn{8}{|c|}{ Q13 A JSGE board-certified instructor of gastroenterology } & $p<0.001$ \\
\hline Yes & 411 & 210 & 71.9 & 9310 & 81.7 & 9520 & 81.5 & $2.21 \%$ \\
\hline No & 220 & 82 & 28.1 & 2082 & 18.3 & 2164 & 18.5 & $3.79 \%$ \\
\hline \multicolumn{8}{|c|}{ Q14 A JSMO board-certified oncologist } & $p=0.001$ \\
\hline Yes & 179 & 113 & 38.7 & 5574 & 48.9 & 5687 & 48.7 & $1.99 \%$ \\
\hline No & 452 & 179 & 61.3 & 5818 & 51.1 & 5997 & 51.3 & $2.98 \%$ \\
\hline Q15 A JSMO board-cert & ified instructor of & ncolo & & & & & & $p=0.004$ \\
\hline Yes & 191 & 120 & 41.1 & 5650 & 49.6 & 5770 & 49.4 & $2.08 \%$ \\
\hline
\end{tabular}


Table 3 (continued)

\begin{tabular}{|c|c|c|c|c|c|c|c|c|}
\hline \multirow[t]{2}{*}{ Questionnaire item } & \multirow[t]{2}{*}{ Department $(N)$} & \multicolumn{2}{|c|}{$\begin{array}{l}\text { Opera- } \\
\text { tive death } \\
(n=292)\end{array}$} & \multicolumn{2}{|c|}{$\begin{array}{l}\text { Alive } \\
(n=11,392)\end{array}$} & \multicolumn{2}{|l|}{ Total } & \multirow[t]{2}{*}{ Mortality rate } \\
\hline & & $N$ & $\%$ & $N$ & $\%$ & $N$ & $\%$ & \\
\hline No & 440 & 172 & 58.9 & 5742 & 50.4 & 5914 & 50.6 & $2.91 \%$ \\
\hline \multicolumn{8}{|c|}{ Q16 A General Clinical Oncologist certified by the Japanese Board of Cancer Therapy } & $p=0.232$ \\
\hline Yes & 563 & 276 & 94.5 & 10,928 & 95.9 & 11,204 & 95.9 & $2.46 \%$ \\
\hline No & 68 & 16 & 5.5 & 464 & 4.1 & 480 & 4.1 & $3.33 \%$ \\
\hline
\end{tabular}

JSGE Japanese Society of Gastroenterology, JSGS Japanese Society of Gastroenterological Surgery, JSHBPS Japanese Society of Hepato-Biliary-Pancreatic Surgery, JSMO Japanese Society of Medical Oncology, JSS Japan Surgical Society, NCD National Clinical Database

*Fisher's exact test

Table 4 The response distributions and relationship between each quality indicator and the crude operative mortality: process indicator

\begin{tabular}{|c|c|c|c|c|c|c|c|c|}
\hline \multirow[t]{2}{*}{ Questionnaire item } & \multirow[t]{2}{*}{ Department no. } & \multicolumn{2}{|c|}{$\begin{array}{l}\text { Opera- } \\
\text { tive death } \\
(n=292)\end{array}$} & \multicolumn{2}{|c|}{$\begin{array}{l}\text { Alive } \\
(n=11,392)\end{array}$} & \multicolumn{2}{|l|}{ Total } & \multirow[t]{2}{*}{ Mortality rate } \\
\hline & & $N$ & $\%$ & $N$ & $\%$ & $N$ & $\%$ & \\
\hline \multicolumn{8}{|c|}{ Q17 Contrast media in CT or MRI to diagnose pancreatic cancer } & $p=0.258^{*}$ \\
\hline Performed in principle & 592 & 281 & 96.2 & 10,931 & 96.0 & 11,212 & 96.0 & $2.51 \%$ \\
\hline Not performed in principle & 2 & 1 & 0.3 & 154 & 1.4 & 155 & 1.3 & $0.65 \%$ \\
\hline Doctor's discretion & 37 & 10 & 3.4 & 307 & 2.7 & 317 & 2.7 & $3.15 \%$ \\
\hline \multicolumn{8}{|c|}{ Q18 MRI of $3 \mathrm{~T}$ or more to diagnose pancreatic cancer } & $p<0.001$ \\
\hline Performed in principle & 285 & 119 & 40.8 & 6330 & 55.6 & 6449 & 55.2 & $1.85 \%$ \\
\hline Not performed in principle & 217 & 101 & 34.6 & 2843 & 25.0 & 2944 & 25.2 & $3.43 \%$ \\
\hline Doctor's discretion & 129 & 72 & 24.7 & 2219 & 19.5 & 2291 & 19.6 & $3.14 \%$ \\
\hline \multicolumn{8}{|c|}{$\begin{array}{l}\text { Q19 Radical resection for cases with Stage } 0-\mathrm{IVa}^{*} \text { pancreatic cancer without invasion of } \\
\text { SMA or CA, or referral to other institutions for radical resection } \\
\text { * General Rules for the Study of Pancreatic Cancer the 6th Edition (the 3rd English Edi- } \\
\text { tion) by Japan Pancreas Society }\end{array}$} & $p=0.018$ \\
\hline Performed in principle & 463 & 238 & 81.5 & 9880 & 86.7 & 10,118 & 86.6 & $2.35 \%$ \\
\hline Not performed in principle & 34 & 14 & 4.8 & 490 & 4.3 & 504 & 4.3 & $2.78 \%$ \\
\hline Doctor's discretion & 134 & 40 & 13.7 & 1022 & 9.0 & 1062 & 9.1 & $3.77 \%$ \\
\hline \multicolumn{8}{|c|}{ Q20 S-1 monotherapy as the first choice in adjuvant chemotherapy for pancreatic cancer } & $p=0.001$ \\
\hline Performed in principle & 305 & 157 & 53.8 & 7205 & 63.2 & 7362 & 63.0 & $2.13 \%$ \\
\hline Not performed in principle & 95 & 36 & 12.3 & 1389 & 12.2 & 1425 & 12.2 & $2.53 \%$ \\
\hline Doctor's discretion & 231 & 99 & 33.9 & 2798 & 24.6 & 2897 & 24.8 & $3.42 \%$ \\
\hline \multicolumn{8}{|c|}{$\begin{array}{l}\text { Q21 Chemoradiotherapy or chemotherapy as the first-line therapy for locally advanced } \\
\text { unresectable pancreatic cancer }\end{array}$} & $p=0.549$ \\
\hline Performed in principle & 413 & 215 & 73.6 & 8701 & 76.4 & 8916 & 76.3 & $2.41 \%$ \\
\hline Not performed in principle & 35 & 15 & 5.1 & 535 & 4.7 & 550 & 4.7 & $2.73 \%$ \\
\hline Doctor's discretion & 183 & 62 & 21.2 & 2156 & 18.9 & 2218 & 19.0 & $2.80 \%$ \\
\hline \multicolumn{8}{|c|}{$\begin{array}{l}\text { Q22 Either gemcitabine monotherapy, gemcitabine plus erlotinib combination therapy, } \\
\text { or S-1 monotherapy as the first-line chemotherapy for locally advanced unresectable or } \\
\text { metastatic pancreatic cancer }\end{array}$} & $p=0.291$ \\
\hline Performed in principle & 391 & 199 & 68.2 & 7644 & 67.1 & 7843 & 67.1 & $2.54 \%$ \\
\hline Not performed in principle & 31 & 10 & 3.4 & 630 & 5.5 & 640 & 5.5 & $1.56 \%$ \\
\hline Doctor's discretion & 209 & 83 & 28.4 & 3118 & 27.4 & 3201 & 27.4 & $2.59 \%$ \\
\hline
\end{tabular}

$C A$ celiac artery, $C T$ computed tomography, $M R I$ magnetic resonance imaging, SMA superior mesenteric artery

*Fisher's exact test 
[0.37-0.66], $p<0.001)$. In contrast, there was no significant difference between the JSHBPS board-certified training institution $\mathrm{B}$ and the institutions that were not boardcertified (Fig. 2b). Although institutions accredited by the JSGE showed a significantly lower AOR (0.50 [0.34-0.74], $p<0.001)$ than those not certified by or related to the JSGE, related institutions showed no significant difference (Fig. 2c). Institutions with an expert surgeon or instructor board-certified by the JSHBPS (Fig. 2i, j), a gastroenterologist or instructor of gastroenterology board-certified by the JSGE (Fig. 2k, l), and an oncologist or instructor of oncology board-certified by the JSMO (Fig. $2 \mathrm{~m}$, n) showed significantly lower AOR values than those without them.

Regarding the use of MRI of $\geq 3 \mathrm{~T}$ for the diagnosis of pancreatic cancer (Q18), both "Not performed in principle" and "Doctor's discretion" were significantly poor risk factors ( $p<0.001$ and $p=0.01$ ) (Fig. 3a). Regarding radical resection (Q19) and S-1 adjuvant chemotherapy (Q20), "Doctor's discretion" showed a significantly higher AOR than "Performed in principle". "Not performed in principle" showed no significant difference in Q19 and Q20 (Fig. 3b, c).

\section{Discussion}

The present study revealed the following three points using questionnaires and the data of the NCD: (1) Mortality of PD was positively affected by the institution certification systems of the JSGS, JSHBPS, JSGE and JSMO. (2) Institutions with an expert or instructor board-certified by the JSHBPS, JSGE or JSMO showed a low PD mortality. (3) The mortality of PD was low in institutions that used MRI of $\geq 3 \mathrm{~T}$ for the diagnosis of pancreatic cancer in principle. These findings suggest to be useful as a QI for PD in Japan.

According to the NCD, the operative mortality of PD between 2011 and 2012 was reported to be lowest in training institution A (board-certified by the JSHBPS) followed by institution $\mathrm{B}$ and non-certified institutions. In addition, the participation of an expert surgeon or instructor who was board-certified by the JSHBPS in PD resulted in a lower operative mortality compared to that with no such participation [17]. The current study, which analyzed NCD data collected between 2013 and 2014, also showed a similar impact of the board certification system of the JSHBPS on the operative mortality of PD. The board certification system of the JSHBPS is suggested to be a good QI in PD for pancreatic cancer.

In contrast, regarding the board certification system of the JSGS, the present study indicated no marked correlation between the operative mortality and the presence of a board-certified expert surgeon or instructor. A previous report showed that the number of expert surgeons boardcertified by the JSGS was a surrogate marker of the operative mortality in eight main procedures, including PD [18]. The present study's lack of an investigation of the number of expert surgeons board-certified by the JSGS might have been associated with the absence of a correlation with the operative mortality. In our study, a favorable outcome of PD was observed in institutions board-certified by the JSGE or JSMO. Furthermore, institutions with experts board-certified by the JSGE or JSMO who did not necessarily participate directly in PD still showed a significantly lower operative mortality for PD than in those without. These results suggest that institutions that specialize in gastroenterology or oncology have more favorable outcomes from surgery due to an indirect effect, as gastroenterologists and oncologists are involved in preoperative care, including oncological judgement, chemotherapy and nutritional management, for patients scheduled for PD. Therefore, these results imply that systematic multidisciplinary approach for preoperative care improves the safety of PD. There are no reports on the relationship between the operative mortality of PD and the board certification systems of the JSGE or JSMO. These are novel findings as factors related to the operative mortality of PD.

To our knowledge, there have been no reports concerning the implementation of clinical practice guidelines for pancreatic cancer, including associations with the mortality of PD. In the present study, institutions using MRI of $\geq 3 \mathrm{~T}$ in principle for the diagnosis of pancreatic cancer had a significantly lower mortality rate of PD than those who did not or did so only at the doctor's discretion (Q18). Although adherence to Q18 was low compared with other QIs, this might be due to the considerable number of institutions unable to perform MRI of $\geq 3 \mathrm{~T}$. Since possession of an MRI machine of $\geq 3 \mathrm{~T}$ depends on a hospital's financial standing, the results of Q18 may reflect the effects of the hospital volume. Interestingly, the present study showed that QIs in radical resection (Q19) and S-1 adjuvant chemotherapy (Q20) had higher AORs for "Doctor's discretion" than for "Performed in principle". In a previous study in this project concerning esophageal cancer, similar results were found in some QIs [13]. These findings suggest the importance of organizational compliance with clinical practice guidelines for pancreatic cancer.

Despite patient selection bias due to old age, which may be considered a factor of non-operative indication, especially in elderly patients with comorbidity, this study demonstrated that age was a significant risk factor for mortality in PD, as previously reported [5]. Mortality following PD for elderly patients with pancreatic cancer has been reported to be affected by specific comorbidities (chronic obstructive pulmonary disease, chronic kidney disease, dementia and sepsis) as patient factors [19]. The present study was conducted with risk adjustment for various patient factors, including the age, as described in the Methods section. However, as a structure indicator, a previous report showed that 

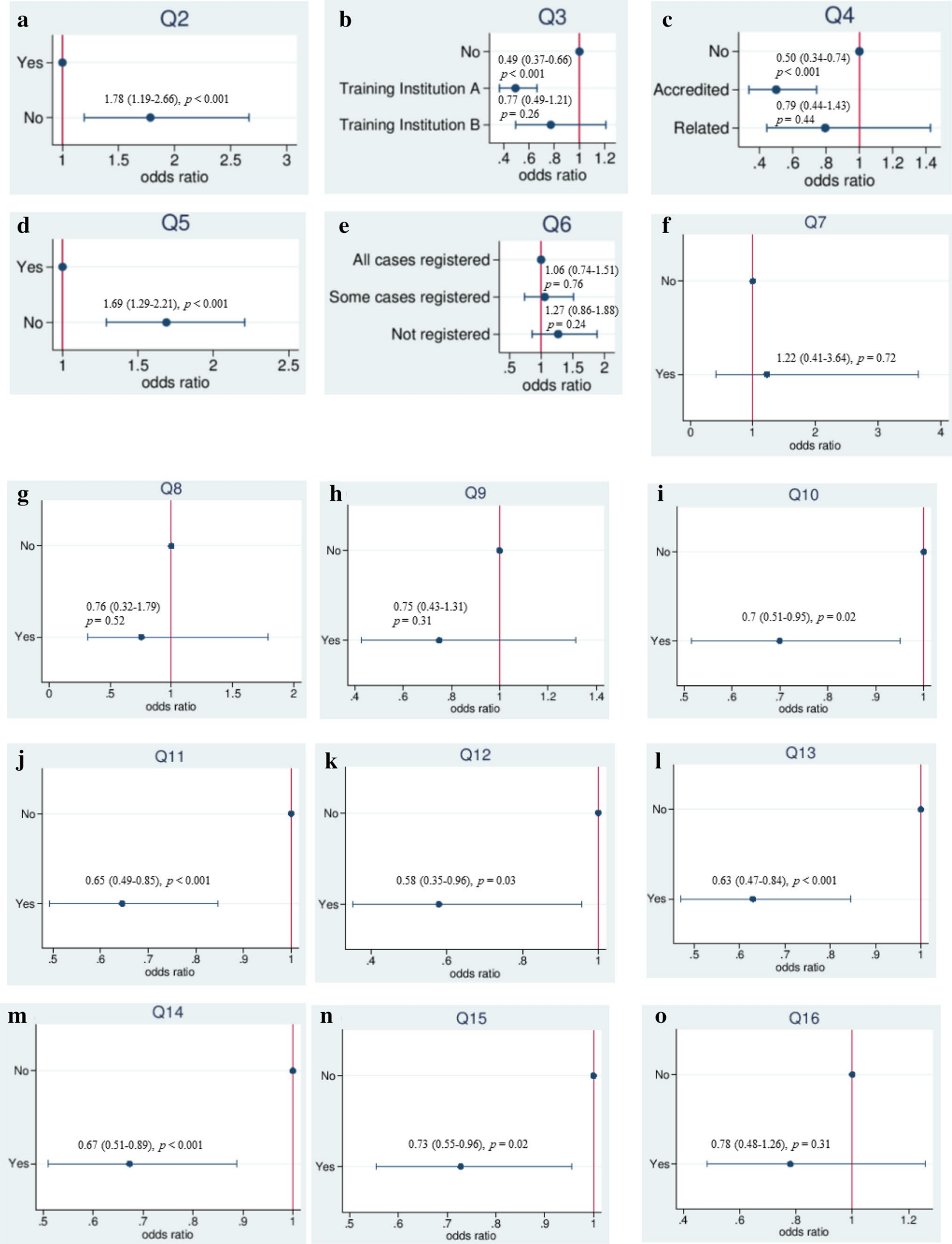
4 Fig. 2 Relationship between each structure indicator and the AOR in PD. a Q2: Institution certified by the JSGS. b Q3: A training institution board-certified by the JSHBPS. c Q4: Institution certified by or related to the JSGE. d Q5: An accredited training facility of the JSMO. e Q6: Registration in the Japan Pancreatic Cancer Registry of the NCD. f Q7: A board-certified instructor of the JSS. g Q8: An expert surgeon of gastroenterological surgery board-certified by the JSGS. h Q9: An instructor of gastroenterological surgery boardcertified by the JSGS. i Q10: An expert surgeon board-certified by the JSHBPS. j Q11: An instructor board-certified by the JSHBPS. k Q12: A gastroenterologist board-certified by the JSGE. I Q13: An instructor of gastroenterology board-certified by the JSGE. m Q14: An oncologist board-certified by the JSMO. $\mathbf{n}$ Q15: An instructor of oncology board-certified by the JSMO. o Q16: A General Clinical Oncologist certified by the Japanese Board of Cancer Therapy

non-teaching hospitals have a higher risk of PD mortality for elderly patients with pancreatic cancer than teaching hospitals [20]. The present study clarified the correlation between the mortality of PD and board certification systems of various academic societies as structure indicators. Thus, the assessment of structural indicators is crucial for reducing the mortality of PD.

The utilization of administrative claims data in Japan for the wide-scale measurement of QIs in the treatment of various cancers, namely colorectal, lung, stomach, liver, breast, prostate and cervical cancer, has been reported [21]. When comparing NCD data with administrative claims data, the advantage is that the impact of QIs on surgical outcomes can be analyzed, as in the current study project [13]. At clinical settings in Japan, the NCD Breast Cancer Registry is used to assess the QIs recommended by the clinical practice guidelines. Registered NCD users can compare the implementation rates of the QIs in their institutes with those of the national average on the NCD web site, which helps eliminate cancer care disparity. Thus, the NCD is a useful tool for evaluating QIs related to each type of cancer.

The limitations of this study are similar to those previously described [13]. First, we cannot exclude respondents' bias in the questionnaire surveys. The respondents were users registered in the NCD and not necessarily representative of the department. In other words, the answers may not necessarily reflect the policies of the department. Second, we received no answer from more than half of the institutions. There may be differences in the implementation rate of QIs or the mortality of PD between respondents and nonrespondents. Third, there may have been selection bias for the QIs, which were selected by discussion among experts of pancreatic diseases, as mentioned above. Finally, PD cases with diseases other than pancreatic cancer were included in this study.

In conclusion, the mortality of PD was positively impacted by the institutional certification systems of the JSGS, JSHBPS, JSGE and JSMO. Institutions with an expert or instructor who was board-certified by the JSHBPS, JSGE or JSMO showed a lower mortality rate of PD than those without such a staff member. Furthermore, institutions performing MRI of $\geq 3 \mathrm{~T}$ for the diagnosis of pancreatic cancer showed a lower mortality from PD than others. The NCD is a useful tool for evaluating the quality of cancer care, especially for analyzing the impact of QIs on surgical outcomes. 
Fig. 3 Relationship between each process indicator and the AOR in PD. a Q18: MRI of $\geq 3 \mathrm{~T}$ to diagnose pancreatic cancer. b Q19: Radical resection for cases with Stage 0-IVa* pancreatic cancer without invasion of SMA or CA, or referral to other institutions for radical resection. c Q20: S-1 monotherapy as the first choice in adjuvant chemotherapy for pancreatic cancer. d Q21: Chemoradiotherapy or chemotherapy as the first-line therapy for locally advanced unresectable pancreatic cancer. e Q22: Either gemcitabine monotherapy, gemcitabine plus erlotinib combination therapy, or S-1 monotherapy as the firstline chemotherapy for locally advanced unresectable or metastatic pancreatic cancer $\mathbf{a}$

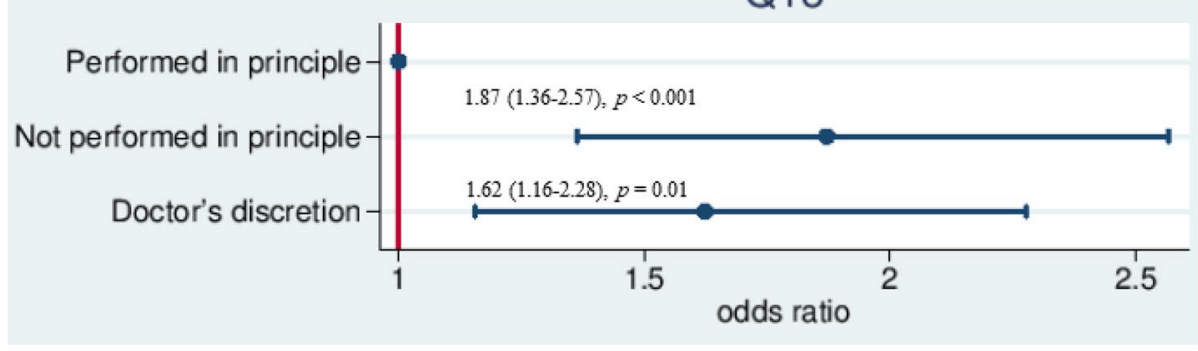

b Q19
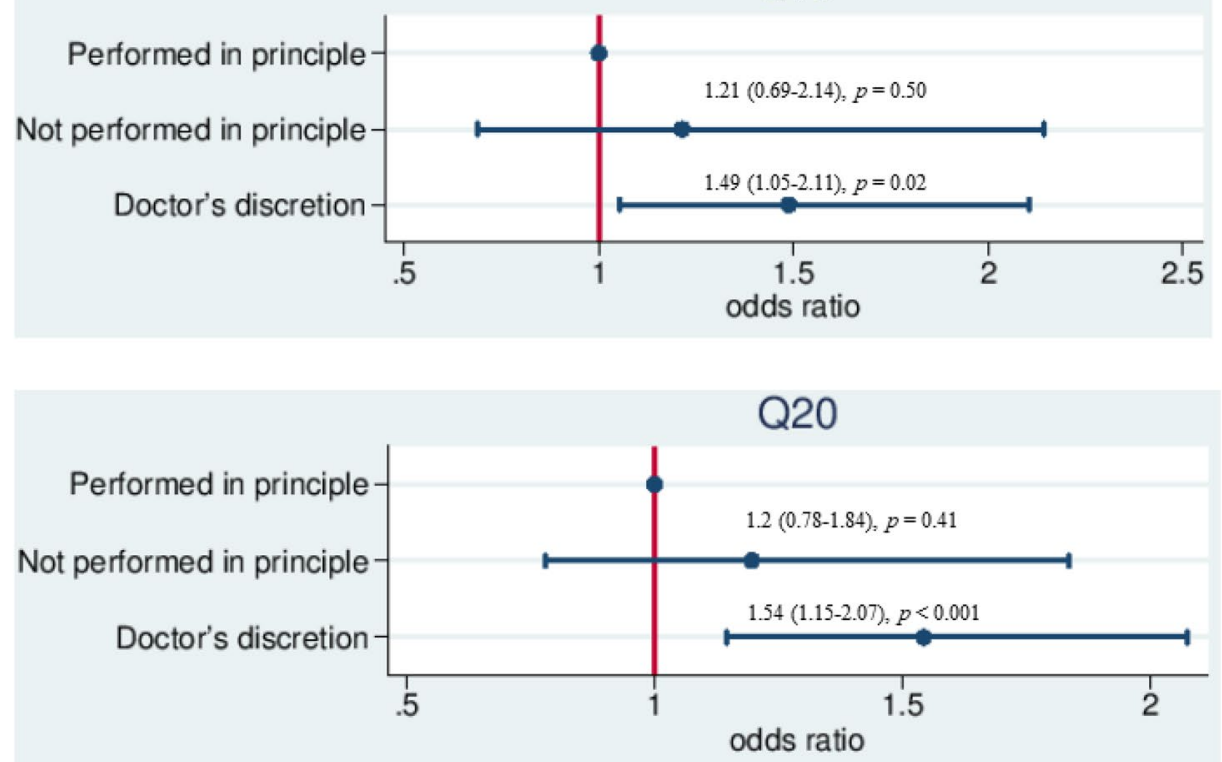

d

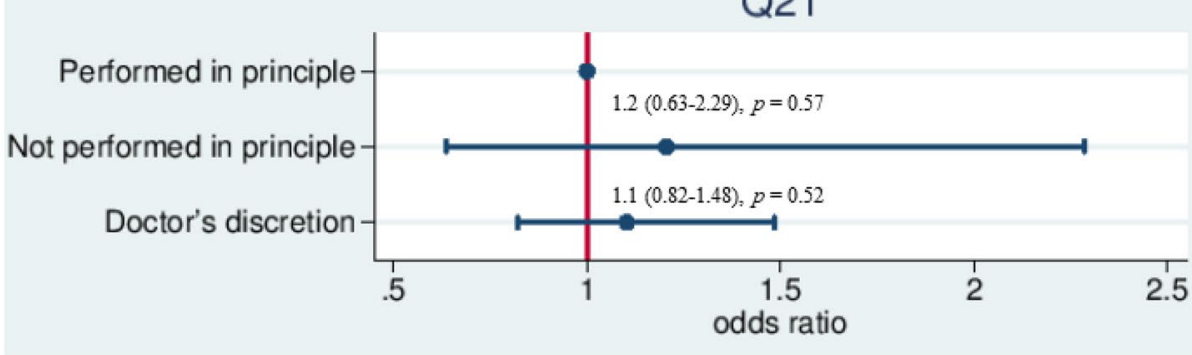

e

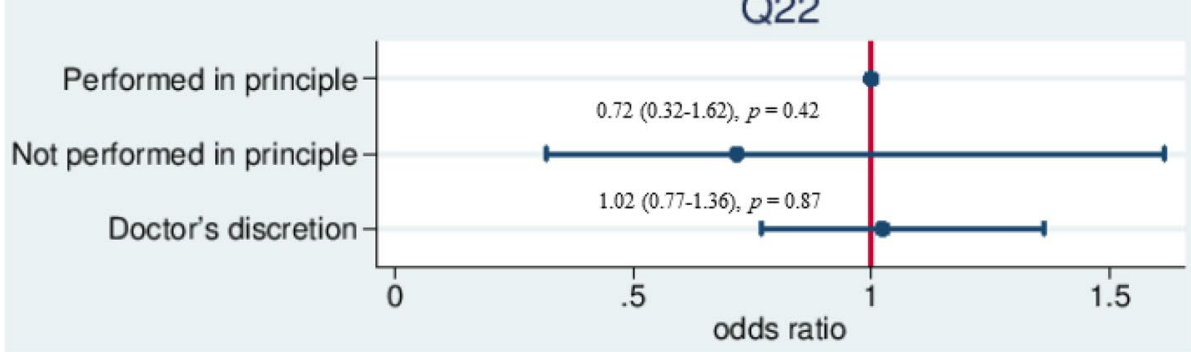

Acknowledgements The authors thank all of the departments and societies related to the NCD for their cooperation in this study. The authors also thank Drs. M. Mori, K. Sugihara, K. Hirata, M. Nagino, T. Ohta, H, Konno, T. Sobue, A. Nashimoto, K. Kotake, N. Kokudo,
M. Yamamoto, M. Tanaka, M. Sato, H. Tokuda and Y. Kitagawa for their cooperation. This work was supported by a grant from the Ministry of Health, Labour and Welfare of the Japan (201221064A) and by 
a grant from Japan Society for the Promotion of Science (16K10437 and 19K09111).

Author contributions MM, HY and MG planned the present study and wrote the manuscript. MM, HY, HM and MG analyzed the data. MU, TS, YT, YK and YS reviewed the manuscript and revised it critically for important intellectual content.

Funding This work was supported by a grant from the Ministry of Health, Labour and Welfare of Japan (201221064A) and by a grant from Japan Society for the Promotion of Science (16K10437 and 19K09111).

\section{Compliace with ethical standards}

Conflict of interest Hiroyuki Yamamoto and Hiroaki Miyata are affiliated with the Department of Healthcare Quality Assessment at the University of Tokyo. The department is a social collaboration department supported by grants from the National Clinical Database, Johnson \& Johnson K.K., and Nipro Co. Other authors have no conflicts of interest.

Open Access This article is licensed under a Creative Commons Attribution 4.0 International License, which permits use, sharing, adaptation, distribution and reproduction in any medium or format, as long as you give appropriate credit to the original author(s) and the source, provide a link to the Creative Commons licence, and indicate if changes were made. The images or other third party material in this article are included in the article's Creative Commons licence, unless indicated otherwise in a credit line to the material. If material is not included in the article's Creative Commons licence and your intended use is not permitted by statutory regulation or exceeds the permitted use, you will need to obtain permission directly from the copyright holder. To view a copy of this licence, visit http://creativecommons.org/licenses/by/4.0/.

\section{References}

1. Lohr KN, Schroeder SA. A strategy for quality assurance in Medicare. N Engl J Med. 1990;322:707-12.

2. Donabedian A. Evaluating the quality of medical care. Milbank Mem Fund Q. 1966;44(Suppl):166-206.

3. Tomotaki A, Kumamaru H, Hashimoto H, Takahashi A, Ono M, Iwanaka T, et al. Evaluating the quality of data from the Japanese National Clinical Database 2011 via a comparison with regional government report data and medical charts. Surg Today. 2019;49:65-71.

4. Hasegawa H, Takahashi A, Kakeji Y, Ueno H, Eguchi S, Endo I, et al. Surgical outcomes of gastroenterological surgery in Japan: report of the National Clinical Database 2011-2017. Ann Gastroenterol Surg. 2019;3:426-50.

5. Kimura W, Miyata H, Gotoh M, Hirai I, Kenjo A, Kitagawa Y, et al. A pancreaticoduodenectomy risk model derived from 8575 cases from a national single-race population (Japanese) using a web-based data entry system: the 30-day and in-hospital mortality rates for pancreaticoduodenectomy. Ann Surg. 2014;259:773-80.

6. Takeuchi H, Miyata H, Gotoh M, Kitagawa Y, Baba H, Kimura W, et al. A risk model for esophagectomy using data of 5354 patients included in a Japanese nationwide web-based database. Ann Surg. 2014;260:259-66.

7. Kurita N, Miyata H, Gotoh M, Shimada M, Imura S, Kimura $\mathrm{W}$, et al. Risk model for distal gastrectomy when treating gastric cancer on the basis of data from 33,917 japanese patients collected using a nationwide web-based data entry system. Ann Surg. 2015;262:295-303.
8. Watanabe M, Miyata H, Gotoh M, Baba H, Kimura W, Tomita $\mathrm{N}$, et al. Total gastrectomy risk model: data from 20,011 Japanese patients in a nationwide internet-based database. Ann Surg. 2014;260:1034-9.

9. Kobayashi H, Miyata H, Gotoh M, Baba H, Kimura W, Kitagawa $\mathrm{Y}$, et al. Risk model for right hemicolectomy based on 19,070 Japanese patients in the National Clinical Database. J Gastroenterol. 2014;49:1047-55.

10. Kenjo A, Miyata H, Gotoh M, Kitagawa Y, Shimada M, Baba $\mathrm{H}$, et al. Risk stratification of 7,732 hepatectomy cases in 2011 from the National Clinical Database for Japan. J Am Coll Surg. 2014;218:412-22.

11. Nakagoe T, Miyata H, Gotoh M, Anazawa T, Baba H, Kimura W, et al. Surgical risk model for acute diffuse peritonitis based on a Japanese nationwide database: an initial report on the surgical and 30-day mortality. Surg Today. 2015;45:1233-43.

12. Matsubara N, Miyata H, Gotoh M, Tomita N, Baba H, Kimura W, et al. Mortality after common rectal surgery in Japan: a study on low anterior resection from a newly established nationwide largescale clinical database. Dis Colon Rectum. 2014;57:1075-81.

13. Toh Y, Yamamoto H, Miyata H, Gotoh M, Watanabe M, Matsubara $\mathrm{H}$, et al. Significance of the board-certified surgeon systems and clinical practice guideline adherence to surgical treatment of esophageal cancer in Japan: a questionnaire survey of departments registered in the National Clinical Database. Esophagus. 2019;16:362-70.

14. Kobayashi H, Yamamoto H, Miyata H, Gotoh M, Kotake K, Sugihara K, et al. Impact of adherence to board-certified surgeon systems and clinical practice guidelines on colon cancer surgical outcomes in Japan: a questionnaire survey of the national clinical database. Ann Gastroenterol Surg. 2020. https://doi.org/10.1002/ ags3.12327

15. Miura F, Yamamoto M, Gotoh M, Konno H, Fujimoto J, Yanaga $\mathrm{K}$, et al. Validation of the board certification system for expert surgeons (hepato-biliary-pancreatic field) using the data of the National Clinical Database of Japan: part 1-Hepatectomy of more than one segment. J Hepatobiliary Pancreat Sci. 2016;23:313-23.

16. The Japan Pancreas Society (Committee for revision of clinical guidelines for pancreatic cancer): clinical practice guidelines for pancreatic cancer based on evidence based medicine (in Japanese). Tokyo: Kanehara Shuppan; 2013.

17. Miura F, Yamamoto M, Gotoh M, Konno H, Fujimoto J, Yanaga $\mathrm{K}$, et al. Validation of the board certification system for expert surgeons (hepato-biliary-pancreatic field) using the data of the National Clinical Database of Japan: part 2-Pancreatoduodenectomy. J Hepatobiliary Pancreat Sci. 2016;23:353-63.

18. Konno H, Kamiya K, Kikuchi H, Miyata H, Hirahara N, Gotoh M, et al. Association between the participation of board-certified surgeons in gastroenterological surgery and operative mortality after eight gastroenterological procedures. Surg Today. 2017;47:611-8.

19. Shia BC, Qin L, Lin KC, Fang CY, Tsai LL, Kao YW, et al. Age comorbidity scores as risk factors for 90-day mortality in patients with a pancreatic head adenocarcinoma receiving a pancreaticoduodenectomy: a national population-based study. Cancer Med. 2020;9:562-74.

20. Shaib WL, Zakka K, Hoodbhoy FN, Belalcazar A, Kim S, Cardona $\mathrm{K}$, et al. In-hospital 30-day mortality for older patients with pancreatic cancer undergoing pancreaticoduodenectomy. J Geriatr Oncol. 2019. https://doi.org/10.1016/j.jgo.2019.10.012.

21. Iwamoto M, Nakamura F, Higashi T. Monitoring and evaluating the quality of cancer care in Japan using administrative claims data. Cancer Sci. 2016;107:68-75.

Publisher's Note Springer Nature remains neutral with regard to jurisdictional claims in published maps and institutional affiliations. 